\section{Treatise on man}

Ian Tattersall

The Cambridge Encyclopedia of Human Evolution. Edited by Steve Jones, Robert D. Martin and David R. Pilbeam. Cambridge University Press: 1992. Pp. 506. £60, $\$ 95$

WHEN any major reference work especially one that has involved the coordination of more than 70 contributors - has spent as long in gestation as this one, two questions immediately spring to mind when it finally appears: "Was it worth the wait?" and "Can it possibly be up to date?". Happily, perusal of The Cambridge Encyclopedia of Human Evolution suggests that the answer to both questions is "yes". But it also evokes a less obvious question: "Is this work properly described as an encyclopaedia?". Here the answer is probably "no", certainly if we compare it with the majority of other encyclopaedias in the Cambridge series, or most especially with its obvious competitor by size and title, the Encyclopedia of $\mathrm{Hu}$ man Evolution and Prehistory, published in 1988 by Garland (in which this reviewer, as a co-editor, must declare an interest - for a review see Nature 335, 598; 1988). The present volume is not an encyclopaedia in the traditional sense, with a large number of entries, alphabetically arranged. Rather, it is better described as a treatise, with about 80 short chapters, some by several authors, grouped into ten main subject areas.

Whether it is adequately described as a treatise on human evolution is yet another question. The editors clearly adhere to the conceit that the study of human evolution legitimately embraces virtually all the principal areas of human biology, stone-age archaeology and primatology; and this shows in the book's extremely broad coverage, which extends to embrace most of the field of physical anthropology. The price paid for this remarkable comprehensiveness is a loss of focus on human evolution proper, which on a liberal estimate accounts for less than half the volume's length.

Such quibbles aside, however, the work provides a feast of information for anyone interested in the history of our species and in the allied disciplines that have contributed to our understanding of this history. The volume opens with a consideration of evolution (long on molecular genetics and short on macroevolution), classification, and the diversity of living primates and how to conserve it. The next sections take up a variety of topics in primate biology, behaviour and social organization, with a particular look at the brain and its role in communication and language. There follows a group of brief contributions on fossils, chronometric dating and taphonomy, and on the influences of climate change and continental movement on evolution; this as a prelude to a short section (only a little over 50 pages) dealing with the primate and human fossil records. The next 80 pages are devoted to a diversity of genetic topics, ranging from the basics of genetics to molecular methods for deducing evolutionary sequences. There's lots of good information here, but the relationship between genetics and evolution remains vague and is mired in a microevolutionary perspective: one searches in vain for any discussion of speciation or of macroevolutionary mechanisms.

The book then proceeds to consider a variety of topics in the reconstruction of early human behaviour and ecology, principally on archaeological evidence and extending up to the domestication of animals and plants. Again, there's plenty of good stuff, but the ten chapters in this section don't quite add up to a coherent account of what the archaeological record can tell us about our past. Following this we arrive at an account of the dispersal and biology of modern human populations, principally from a genetic and demographic perspective, as a prelude to the by now almost obligatory consideration of our species' evolutionary future. Once more the perspective is microevolutionary, but from an entirely different vantage point I would unhesitatingly fall in with the view articulated here that innovation in human evolution is virtually at an end. A final section of appendices provides potted biographies of historical worthies, a Cenozoic timescale, a world map of principal human fossil sites and a glossary of terms.

No work with over 70 authors could ever hope to be a completely comprehensive, consistent and seamless account of a wide-ranging area of science, and it would be pointless to criticize this remarkable volume for failing on any of these scores. It is much more appropriate to focus on the extraordinary variety of information that has been packed between its covers. Nobody will be able to browse through this book without discovering something new; a fairly comprehensive index (and a little crossreferencing in the text) will in some measure compensate for its structural dissimilarity to traditional encyclopaedias; it is bang up to date (how often has a book arrived on your desk that contained a reference to an article published only three months earlier?); and if its view of evolution is a trifle oldfashioned, it does no more than reflect the state of the art in its field. If (whether student or professional) you're interested in human evolution, you'll want to have this volume handy.

Ian Tattersall is in the Department of Anthropology, American Museum of Natural History, New York, New York 10024, USA.

\section{Goodbye to Gutenberg?}

\section{Graham Dunn}

Light Microscopy: An Electronic Textbook. By D. J. Rawlins. Bios Scientific: 1992. £52.88 (UK and EC), £45, \$90 (elsewhere) (single licence); $£ 158.63$ (UK and EC), £135, \$270 (e/sewhere) (department licence).

ENTER the world's first electronic textbook on light microscopy. Will the two $3 \frac{1}{2} 2$-inch floppy disks held in my trembling fingers herald a new age in which printing will become obsolete and teachers redundant? My disillusionment was slow but profound. Slow because this was no ordinary book that could be scanned simply by flicking pages, and profound because it might as wel! have been. Or at least it might have made a modest pamphlet: I estimate that the total textual content of "over 200 pages of information" would fit comfortably on six pages of Nature. Certainly it would then be easier to read but it would be harder to justify the "in-depth coverage" proclaimed by the advertising leaflet, or for that matter, the price.

To be fair though, the bulk of the information contained in the electronic textbook is devoted to producing images, not text, and a few of these approach the quality of colour photographs. But even these would be better printed on glossy paper, because no animations or computational techniques are applied to them. Computers do have an important role as teaching aids but only if their ability to perform computations and selectively guide the user's access to a large body of information is exploited. Little of this kind is on offer here and I feel that an exciting opportunity has been missed. Teachers of light microscopy may breathe again - for a while.

Graham Dunn is in the MRC Muscle and Cell Motility Unit, King's College, 26-29 Drury Lane, London WC2B 5RL, UK.

Also just published by Bios Scientific is D. J. Rawlins's Light Microscopy, a "complementary book for first-time users". Pp. 156. £14.50, \$29. 